\title{
o Programa Mais Médicos no contexto das estratégias de mudança da formação médica no país: reflexões e perspectivas
}

\section{Mais Médicos Program in the context of changing strategies of medical training in the country: reflections and perspectives}

\author{
Maria Claudia Matias ${ }^{a}$ \\ (D) https://orcid.org/0000-0002-3707-3946 \\ E-mail: claudiamatias2005ळyahoo.com.br \\ Marta Verdi ${ }^{b}$ \\ (D) https://orcid.org/0000-0001-7090-9541 \\ E-mail: marverdiळhotmail.com \\ Mirelle Finkler ${ }^{c}$ \\ (D) https://orcid.org/0000-0001-5764-9183 \\ E-mail: mirelle.finklerळufsc.br

\section{Marco Aurelio Da Ros ${ }^{d}$} \\ (D) https://orcid.org/0000-0003-4370-3120 \\ E-mail: rosळunivali.br \\ aPrefeitura Municipal de Blumenau. Secretaria de Promoção da \\ Saúde. Blumenau, SC, Brasil. \\ bUniversidade Federal de Santa Catarina. Departamento de Saúde \\ Pública. Florianópolis, SC, Brasil. \\ 'Universidade Federal de Santa Catarina. Departamento de \\ Odontologia. Florianópolis, SC, Brasil. \\ ¿Universidade do Vale do Itajaí. Programa de Pós-Graduação \\ em Saúde e Gestão do Trabalho. Itajaí, SC, Brasil.
}

\section{Resumo}

A formação profissional, como estratégia de sustentabilidade da política pública de saúde, precisa se aproximar das necessidades do Sistema Único de Saúde (SUS) brasileiro. Nesse contexto, a formação médica tem capitaneado grande parte das iniciativas governamentais voltadas à mudança no modelo formador em saúde. A mais recente, empreendida via Programa Mais Médicos (PMM), tem gerado um debate polêmico e revelador do jogo de forças e interesses que interferem no problema da insuficiência de vagas e da baixa efetividade da formação no que tange às necessidades do SUS. Essas forças, por condicionarem os rumos do processo de ampliação e reestruturação da formação médica, e isso inclui implicitamente todos os cursos da área da saúde, demandam análise histórica e acompanhamento crítico dos movimentos em curso no país. Nesse sentido, as reflexões aqui aportadas visam contribuir na potencialização do PMM como dispositivo de interferências no campo, capaz de agregar novas dimensões ao processo formativo do médico e, ao fazê-lo, repercutir em todos os cursos da área da saúde.

Palavras-chave: Programa Mais Médicos; Educação Médica; Formação Profissional em Saúde; Atenção Primária à Saúde; Sistema Único de Saúde.

\section{Correspondência}




\section{Introdução}

The professional training as a sustainability strategy of public health policy has to approach the needs of the Brazilian National Health System (SUS). Therefore, medical training has been the object of many governmental initiatives aimed at changing the training model. Recently, there has been a controversial and revealing debate of forces and interests that interfere in the problem about lack of vacancies and little training effectiveness regarding the SUS needs through the Mais Médicos Program (PMM) model. These forces condition the process of expansion and restructuring course of medical training and require a historical analysis and critical follow-up of the movements in progress, in the country. Thus, the reflections provided here aim to contribute to the PMM potentiation as an interference device in the field, and capable of adding new dimensions to the training process.

Keywords: Mais Médicos Program; Medical Education; Professional Training in Health; Primary Health Care; Brazilian National Health System.
Pensar o tema da formação em saúde voltada à atuação no Sistema Único de Saúde (SUS) tem sido um instigante modo de conectar as diversas e complexas necessidades e carências que o rondam. A sustentabilidade da política pública de saúde tem se articulado ao debate sobre as insuficiências da formação, confrontando-se com os desafios colocados por práticas educacionais ainda frágeis na resposta à atuação desejada pelo modelo de gestão e de atenção à saúde preconizado pelo sistema.

A complexidade do trabalho em saúde assentase em uma prática reflexiva que considere as várias dimensões das necessidades de saúde e da relação estabelecida no encontro de usuários e trabalhadores. No entanto, o cenário de práticas em que a formação em saúde tem se dado é marcado pela dificuldade das equipes em dar conta de um modelo assistencial universal, equânime, interdisciplinar e centrado no cuidado integral. A defasagem na formação das equipes que hoje atuam no SUS coloca para o ensino o desafio de ampliar os espaços de reflexão e de compartilhamento de saberes sobre o cotidiano do cuidado realizado nos serviços (Junqueira; Frutuoso, 2013).

Desse modo, avançar nos processos formativos, para que sejam críticos e propositivamente comprometidos com a defesa e o aprimoramento do modelo de atenção preconizado no SUS e pelas Diretrizes Curriculares Nacionais (DCN), tem sido o objetivo dos esforços de qualificação da formação em saúde para o SUS. A iniciativa governamental mais recente, empreendida via Programa Mais Médicos (PMM), gerou um debate polêmico e bastante revelador das tensões do campo (Campos; Pereira Júnior, 2016). A polarização de corporações profissionais, movimentos sociais, instituições da saúde e do ensino quanto às estratégias de provimento profissional e de mudança da formação médica propostas pelo PMM deu algum grau de visibilidade ao jogo de forças e interesses que interferem no problema da insuficiência de médicos e da inadequação da formação ao SUS. Atualizadas diante da proposta do PMM para a mudança da formação médica, essas forças têm incidido nos rumos tanto da implantação dos novos cursos de 
medicina no país quanto da adequação dos cursos já existentes nas propostas do Programa.

Este artigo de reflexão, baseado em uma análise crítica da revisão bibliográfica realizada para a tese de doutoramento $O$ desafio ético-estético-político do SUS para a formação médica (Matias, 2017), pretende analisar as iniciativas de mudança da formação médica empreendidas nas três últimas décadas, discutindo a possível contribuição do PMM tanto no sentido das suas propostas quanto no que tem gerado de visibilidade acerca das forças envolvidas nesse campo e dos desafios que o Programa terá que enfrentar.

\section{Os movimentos pela mudança da formação médica}

Para compreender o alcance da inflexão proposta pelo PMM quanto à formação médica, é pertinente olhar para o contexto histórico dessa formação no país e analisar as forças e movimentos que, desde outros países e momentos históricos, foram determinantes nesse processo. A importação de modelos externos, principalmente o biomédico, é um dos movimentos que mais fortemente tem condicionado o cenário da formação em saúde no país. Esse modelo, centrado na doença, em sua dimensão individual e biológica, foi consolidado a partir do relatório Flexner, de 1910, que versava sobre a qualidade da formação médica nos Estados Unidos e no Canadá. Esse relatório foi a principal referência para a acreditação de escolas médicas nesses dois países durante a primeira metade do século XX. Quanto ao alcance do relatório Flexner na produção do modelo biomédico, uma extensa produção científica atribui a fundação desse modelo como um dos efeitos do referido relatório. No entanto, Almeida Filho (2010), ao analisar o texto original do relatório e se aprofundar na biografia de Flexner, extrai uma conclusão distinta: por questões conjunturais, relacionadas ao contexto político da formação médica da década de 1970, a maior parte das publicações teria focalizado aspectos parciais do relatório, tornando personalizada e incompleta a compreensão do papel histórico de Abraham Flexner para a formação médica. 0 autor refere a criação intencional de uma certa "mitologia política" em torno de Flexner que teria ajudado a dar notoriedade à crítica da formação calcada na biomedicina, na medida em que localizou e personalizou a autoria da proposição desse modelo, gerando como consequência efeitos imaginários de exclusão, negatividade e repulsa ao relatório e ao autor.

Como colocam Pagliosa e Da Ros (2008), o relatório Flexner teve múltiplos usos, "para o bem e para o mal”, como se intitula o referido artigo. Serviu para justificar uma antiga e desejosa aproximação da indústria farmacêutica e de grupos responsáveis pelas publicações médicas, fortalecendo a associação entre a corporação médica, o grande capital e as universidades. Teria também impulsionado o movimento de institucionalização da chamada medicina científica. No entanto, paradoxalmente, segundo Almeida Filho (2010), teria fornecido subsídios para a sistematização e a visibilidade da crítica a esse mesmo modelo. Não seria a primeira vez que interesses antagônicos se ancorariam em uma mesma produção acadêmica para distintas finalidades.

À medida que o modelo de formação biomédico se consolidou, focando o currículo somente na aprendizagem em laboratórios e hospitais, não incluiu a dimensão psicossocial e coletiva do processo saúde-doença-atenção, distanciando-se das necessidades da população e da organização dos sistemas de saúde. A formação para a Atenção Primária à Saúde (APS) ou Atenção Básica (AB) foi constituindo-se à sombra do modelo biomédico, perdendo em parte a dimensão de amplitude à qual deveria corresponder. Tal fato gerou, a partir da década de 1960, um movimento mundial de crítica, ativado por instituições da saúde e governos de diversos países, que veio a deflagrar a reforma da formação médica e do setor da saúde nos anos 1980 (Pagliosa; Da Ros, 2008).

No Brasil, o tema da formação para o setor público de saúde esteve presente nas proposições do movimento da Reforma Sanitária, na $8^{a}$ Conferência Nacional de Saúde e na $1^{\text {a }}$ Conferência Nacional de Recursos Humanos para a Saúde, em 1986, sinalizando a necessidade de modificação nas graduações e a importância da integração ensino-serviço. Em 1981, a iniciativa coordenada pelo Ministério da Educação (MEC) denominada Programa de Integração Docente Assistencial 
(IDA) voltava-se a projetos que promoviam a inserção dos alunos em unidades de APS. Mas o IDA limitava-se à assistência em saúde, o que não interferiu significativamente nos currículos. $\mathrm{Na}$ década seguinte, a Fundação Kellogg financiou o Projeto Uma Nova Iniciativa, centrado na multiprofissionalidade, nos Sistemas Locais de Saúde, na epidemiologia e no fortalecimento do currículo via estágio na comunidade como estratégia para superar a dissociação entre teoria e prática (Chaves; Kisil, 1999; Gonzalez; Almeida, 2010). Ainda na década de 1990, a Associação Brasileira de Ensino Médico, o Conselho Federal de Medicina (CFM), a Direção Executiva Nacional dos Estudantes de Medicina e a Associação Nacional dos Docentes do Ensino Superior articularam-se com outras instituições e criaram a Comissão Interinstitucional de Avaliação do Ensino Médico (Cinaem). Essa comissão realizou avaliações aprofundadas do ensino médico por uma década e foi o motor das tentativas de mudança iniciadas no novo século (Carvalho, 1998).

Com a implementação do SUS na década de 1990, o Ministério da Saúde passou a ordenar a formação, conforme preconizado pela Constituição Federal, mas com insuficiente articulação com o MEC. As propostas de mudança elaboradas nas décadas de 1980 e 1990 não avançaram suficientemente na articulação política e na construção de consensos acerca do modelo de formação médica. A crítica acerca da fragmentação do ensino produzida pela introdução de especialidades na graduação ficou obscurecida por uma discussão que, no fundo, tinha como tema a função social do médico. Outro problema foi apostar excessivamente na mudança do cenário de aprendizagem e nas estratégias pedagógicas como fatores suficientes para articular as disciplinas básicas com a clínica, ou achar que a capacitação para a metodologia científica daria conta de desenvolver o raciocínio clínico.

Ao final da década de 1990, a baixa qualificação do trabalho docente, a carga horária excessiva, a pouca produção de conhecimento, a inadequação dos cenários e a incorporação indiscriminada de tecnologias ainda apareciam entre os principais problemas apontados nas avaliações da formação médica no país (Feuerwerker, 1998, 2002; Pagliosa; Da Ros, 2008; Schraiber, 1993).
Nesses movimentos de mudança na formação, destaca-se o encapsulamento de iniciativas compostas apenas por aqueles que já estavam sensíveis e mobilizados para a necessidade de mudar. As propostas que não agregaram diferentes grupos, fomentando a crítica ao antigo modelo de formação, tiveram pouca chance de ser exitosas, bem como aquelas que partiram de grupos com baixo poder de interferir nos rumos institucionais. As experiências de mudança que lograram maior êxito foram, em geral, gestadas em contextos de alta governabilidade institucional, demandando dos grupos que delas se ocuparam a ocupação de cargos com maior poder decisório. Igualmente, a adoção isolada dessa estratégia, sem outras que ampliassem a capacidade crítica dos grupos conservadores sobre os modos de formar, pode ter contribuído para ampliar a fragmentação das concepções, perpetuando disputas que dificultaram produção de consensos e articulação política para a mudança do modelo (Schraiber, 1993).

Nos anos 2000 , sob influência ainda das avaliações realizadas pela Cinaem, o foco das ações governamentais recaiu sobre a graduação em medicina. O Programa de Incentivo às Mudanças Curriculares das Escolas Médicas (Promed), lançado pelo Ministério da Saúde, em dezembro de 2001, em parceria com o MEC e a Organização PanAmericana de Saúde, propunha-se a incentivar as escolas médicas do país a adequar seus currículos, sua produção de conhecimento e os programas de educação permanente à realidade social e de saúde da população brasileira, ofertando apoio financeiro para implementar as ações. O Promed alcançou 19 escolas médicas (Souza; Zeferino; Da Ros, 2011).

Como ampliação do Promed, em 2005, foi instituído o Programa Nacional de Reorientação da Formação Profissional em Saúde (Pró-Saúde), abarcando também, além da medicina, os cursos de enfermagem e odontologia. Com foco na aproximação ensino-serviço e na abordagem integral do processo saúde-doença desde a $\mathrm{AB}$, apostou em um modelo de formação que considera fortemente os aspectos socioeconômicos e culturais da população para a produção do cuidado (Cezar et al., 2010; Oliveira et al., 2015; Pagliosa; Da Ros, 2008). 
Em 2008, como consequência dos avanços do Pró-Saúde, foi instituído o Programa de Educação pelo Trabalho para a Saúde. Por meio de vivências e estágios na rede de serviços que qualificam a iniciação ao trabalho, fortaleceu a parceria interministerial entre saúde e educação e colocou centralidade nas necessidades dos serviços, que passaram a ser objeto de investigação e de produção do conhecimento, indissociando ensino, pesquisa e extensão (Brasil, 20o8).

Com o objetivo de articular instituições de formação e o sistema de saúde, essas iniciativas apostaram em estratégias pedagógicas voltadas à diversificação dos cenários de ensino-aprendizagem desde o primeiro período, fortalecendo a orientação das DCN, que colocavam para o SUS o papel de receber os graduandos já nos períodos iniciais do curso. Outra aposta pedagógica referia-se à utilização de metodologias ativas de ensinoaprendizagem, especificamente a Aprendizagem Baseada em Problemas, como modo de colocar o graduando como protagonista de sua formação (Costa et al., 2014).

A ordenação das vagas de residência médica a partir das demandas colocadas pelos serviços de saúde é outro antigo desafio enfrentado pelo SUS no âmbito das políticas de formação em saúde no Brasil. Essa formação lato sensu, baseada no treinamento em serviço, teve grande expansão nas últimas décadas. As atividades práticas na graduação mostraram-se insuficientes para o adequado desenvolvimento das competências necessárias à prática médica, elevando a residência à condição de etapa da formação quase que indispensável ao adequado exercício profissional. Mas, mesmo sendo uma formação financiada em grande parte com recursos públicos, desenvolvida em serviços públicos e acreditada por um órgão público, sua regulação até meados dos anos 2000 era caracterizada pela aleatoriedade e insuficiência na distribuição de vagas. Assim, em 2009 os Ministérios da Saúde e da Educação, cientes da escassez de especialistas, criaram o Programa Nacional de Apoio à Formação de Médicos Especialistas em Áreas Estratégicas, voltado à expansão dos programas de residência em regiões e especialidades prioritárias para o SUS (Brasil, 2015).
Em 2011, a criação do Programa de Valorização do Profissional da Atenção Básica (Provab) articulou-se às políticas criadas para responder aos déficits de provimento e dificuldades de fixação de médicos em várias regiões. O Programa visava tanto estimular o aprimoramento para a atuação de profissionais graduados na $\mathrm{AB}$, quanto prover profissionais em áreas de difícil acesso ou maior vulnerabilidade. A oferta era de trabalho supervisionado, juntamente com especialização lato sensu em $\mathrm{AB}$ e um percentual de $10 \%$ na pontuação para o processo seletivo da residência médica. A ação recebeu destaque por promover espaços de compartilhamento e problematização da realidade, por trabalhar com o conceito de cuidado de modo ampliado em situações de escassez de médicos, criando alternativas aos modos de cuidar médico-centrados, e por proporcionar às universidades aproximação dos profissionais recém-formados e, assim, identificar as insuficiências da graduação (Brasil, 2013).

No entanto, o Provab acabou acontecendo majoritariamente nos grandes centros ou no litoral, teve supervisão insuficiente e não interferiu satisfatoriamente na fixação dos médicos nos postos de trabalho. $O$ fato de buscar a valorização dos profissionais da $\mathrm{AB}$ utilizando como atrativo o acréscimo na nota para ingresso na residência foi visto por alguns como um erro de estratégia, pois esse incentivo estimularia os profissionais a deixar seus postos. Não obstante, não deixa de ser interessante observar a fixação provisória na $A B$ e o contato com ela pelos futuros residentes nas especialidades que tenham formação e experiência prévia na AB (Feuerwerker, 2013). Nesse período, a maioria dos profissionais ainda apresentava relatos de despreparo e desmotivação (por questões culturais e mudança de valores) para enfrentar a fixação em localidades do interior e os desafios da tecnologia leve que caracterizam a atuação na AB. Tal situação refletia - e ainda reflete - a sedução que o trabalho nos grandes centros, a especialização em tecnologias duras, os altos salários, o consultório privado, o hospital e a especialidade de ponta ainda exercem sobre essa formação. Outros desafios localizavam-se nos próprios cursos de medicina, que focalizavam a construção de conhecimentos biomédicos em detrimento do desenvolvimento de habilidades e 
atitudes, como modo de atender às exigências, e seduções de um mercado que opera na lógica do capitalismo tardio e das sociedades de controle. Em geral, os docentes desses cursos foram formados no modelo disciplinar cartesiano, apresentando lacunas em sua formação éticopolíticopedagógica, tais como a dificuldade de articular os saberes de modo interdisciplinar (Costa et al., 2014).

Percebe-se que alguns desafios persistem sem respostas efetivas. Entre os dissensos clássicos da mudança do modelo formador estão aqueles relacionados ao processo de acumulação capitalista, à deficiente organização do trabalho e da atenção à saúde (pública e privada), ao papel social da medicina, às dificuldades nas relações médico-paciente e às disputas pela missão da universidade. Evidenciam-se os impasses acerca do lugar da subjetividade, dos afetos, das emoções e da coletividade, em função da tendência reducionista e biologicista, amplificada pelo complexo médicoindustrial, que ainda atravessa as ciências da saúde. Somam-se a isso os déficits da escolarização prévia, que não tem efetivado uma educação humanística já prevista na Lei de Diretrizes e Bases da Educação Nacional de 1996, e que produzem uma perigosa lacuna em termos de sensibilidade e competência moral, necessárias para o exercício da cidadania crítica e ativa, capaz de enfrentar as desigualdades e injustiças sociais típicas das sociedades capitalistas (Silva Junior; Andrade, 2016). Persistem também os déficits decorrentes da distância entre as propostas curriculares e as reais necessidades de saúde da população, compondo um cenário no qual os conteúdos trabalhados na formação em saúde nem sempre são selecionados a partir de critérios epidemiológicos e sociais. Foi com esse conjunto de desafios no horizonte da formação médica que nasceu a proposta do PMM.

\section{A proposta de mais médicos para país}

O PMM é oriundo de um contexto de reivindicações, principalmente quanto ao déficit de provimento de profissionais, que se agravou com a expansão dos serviços públicos de saúde no início da década de 2010, ano em que houve aumento da renda e a diminuição das taxas de desemprego. Em 2013, a distribuição dos profissionais médicos no Brasil, segundo o levantamento do CFM, chegava a 1,8 por mil habitantes, média que, associada a uma distribuição deficitária em algumas regiões do país, configurava uma realidade desigual. Somente $8 \%$ do total de médicos estavam atuando em municípios com população inferior a 50 mil habitantes, que representam 90\% das cidades do país. A insuficiência de vagas na formação médica a cada ano agravava ainda mais a situação. De 2002 a 2012, chegou a gerar uma demanda reprimida de 50 mil profissionais, pois, dos 143 mil novos postos de trabalho, apenas 93 mil foram preenchidos (Brasil, 2015).

Apesar do alto número de escolas médicas, o número de vagas oferecidas era e ainda é insuficiente e mal distribuído no território nacional, ocasionando um déficit que impacta a $\mathrm{AB}$ de diferentes formas. Além de ser um dos principais condicionantes da expansão da Estratégia de Saúde da Família, a insuficiência de médicos coloca os municípios em disputa pelos profissionais disponíveis, obrigandoos a propostas salariais não compatíveis com os recursos municipais. Tal situação eventualmente gera atrasos salariais, quebras de contrato e a imposição aos médicos de jornadas reduzidas de trabalho, não compatíveis com as necessidades dos serviços. Esse quadro tem suscitado irregularidades e ilegalidades nos serviços, além de dificultar o acesso e prejudicar a qualidade da assistência, já que pouco mais da metade dos médicos completa um ano de atuação no mesmo município (Brasil, 2015).

Em janeiro de 2013, prefeitos recém-eleitos de todo o país, reunidos no Encontro Nacional de Prefeitos, manifestaram-se publicamente no movimento denominado "Cadê o médico?". Uma petição foi encaminhada ao Governo Federal reivindicando a contratação de médicos estrangeiros, alegando a falta de médicos, principalmente para o interior, periferias e regiões de vulnerabilidade social. Como resposta, e em um contexto no qual o Ministério da Saúde buscava enfrentar os fatores condicionantes do baixo desenvolvimento da $\mathrm{AB}$, em julho de 2013 foi instituído o PMM para o Brasil (Comes et al., 2016).

Entre os objetivos que o PMM busca atingir estão: a diminuição da carência de médicos nas 
regiões prioritárias; o fortalecimento da prestação de serviços de AB; o aprimoramento da formação médica no país (ampliando o campo de prática durante a formação); a ampliação da inserção do médico em formação nas unidades do SUS; o fortalecimento da política de educação permanente, via integração ensino-serviço; o fomento da troca de conhecimentos e experiências entre profissionais brasileiros e estrangeiros; o aperfeiçoamento para atuação nas políticas públicas de saúde e na organização e funcionamento do SUS; e o estimulo à realização de pesquisas aplicadas ao SUS (Brasil, 2015).

Além de buscar impactar diretamente o problema do provimento de profissionais, o Programa buscou incidir sobre a relação do SUS com a categoria médica, pela via da reorientação da formação colocada na Lei $\mathrm{n}^{0} 12.871 / 2013$, que abrange todas as escolas médicas: públicas e privadas, novas e já existentes. Diferentemente das DCN publicadas em 2001, essa lei exigiu a implantação efetiva de novas diretrizes (2014), colocando a obrigatoriedade de que todas as escolas médicas as implantassem progressivamente até 31 de dezembro de 2018 (Silva Junior; Andrade, 2016).

A alteração da lógica da expansão de vagas nos cursos de graduação deveria incorporar a regulação e o planejamento empreendidos pelo Estado, em que as necessidades sociais definem quais, onde e quantos novos profissionais são necessários. A ampliação da formação colocada pelas DCN de 2014 trouxe mais centralmente para a formação campos de saber e de prática vinculados à saúde coletiva, à saúde mental, à urgência e emergência, à $\mathrm{AB}$ e à saúde da família (Campos; Pereira Júnior, 2016).

As novas DCN referendam o protagonismo do aluno e a integração ensinopesquisaextensão que já apareciam nas diretrizes de 2001, buscando aproximar-se das tecnologias de informação e comunicação. Dão continuidade também à ideia de formação vinculada às necessidades de saúde da população, reforçando uma abordagem integral do cuidado e priorizando-a em detrimento da atenção focada na doença. Exortam a construção de projetos terapêuticos que incluam o sujeito e seu contexto de vida, corresponsabilizando-o pela produção e gestão do seu cuidado. A integração entre atenção e cuidado à saúde, educação e gestão preconizada nas DCN, expressa um modelo de formação que considera as instituições de saúde como organizações voltadas à atenção, à formação, à educação permanente e que têm como modo de gestão práticas que incluem a decisão coletiva e a participação. É relevante pontuar que as DCN preconizam uma formação médica voltada também à participação dos graduandos nas políticas públicas de saúde e na gestão do SUS. Ao lado dos demais objetivos, vinculados à atuação na atenção à saúde, esse tópico merece destaque. Ele enfatiza a expectativa de que os profissionais médicos ampliem sua capacidade de interferência nas práticas de gestão do Sistema, colocando a formação como possível estratégia de sustentabilidade e qualificação das políticas públicas de saúde (Feuerwerker, 2002; Gomes; Rego, 2014).

A ampliação direcionada de vagas para a graduação e para a residência é uma das estratégias para superar o déficit que em 2013 chegava a 168.424 médicos, avançando de 1,8 para 2,7 médicos por mil habitantes até 2026. Os critérios para abertura de vagas consideram a necessidade social no âmbito público e privado e a descentralização e interiorização das faculdades. Apesar de não existir um parâmetro validado internacionalmente para o cálculo do número de médico por habitantes, há recomendação de se analisar as características do país, como o modelo assistencial adotado, por exemplo. A meta eleita inspirou-se no contexto do Reino Unido, que, a exemplo do Brasil, também conta com um sistema de saúde público universal orientado pela AB. Devido a essa realidade, a abertura de novos cursos ganhou caráter de processo público e a participação das instituições deveria estar condicionada ao atendimento de critérios padronizados, como a comprovação de rede de serviços de saúde disponível, a adequação do porte populacional, a localização em região prioritária, a proporção da oferta de vagas e de médicos na região e a distância mínima em relação a outros cursos. Para a efetiva fixação de médicos no interior do país, há que se superar o desafio de associar outras estratégias à interiorização dos cursos de medicina. Medidas regulatórias e incentivos desde a formação, passando pelas etapas de recrutamento, instalação, fixação e plano de carreira são necessários para consolidar uma distribuição equitativa e a permanência de 
médicos em postos de trabalho mais distantes dos grandes centros (Scheffer, 2016). Pelos parâmetros propostos pelo PMM, alinhados às novas DCN, observa-se que boa parte do internato (dois anos) se dá no SUS, na $A B$ e em serviços de urgência e emergência. A partir de 2018, cursar um ou dois anos da residência em Medicina Geral de Família e Comunidade (MGFC) também passará a ser requisito para acessar as especialidades que não são de acesso direto. Até o final de 2018, espera-se que haja o mesmo número de vagas de residência de acesso direto que o número de egressos dos cursos de graduação do ano anterior (Brasil, 2013). Após amplo debate junto com a sociedade, viu-se uma gradativa ampliação da aprovação popular do PMM e um acirramento da oposição de grupos vinculados à corporação médica, visto que ainda há muita disputa em torno das concepções envolvidas na formação, como a da função social do médico, e conflitos de interesses que cercam o problema do provimento profissional. A forte inserção dos graduandos e pós-graduandos nos serviços públicos de saúde tem sido criticada por parte significativa da corporação e também por outros setores. No entanto, é sabido que a aproximação com o sistema de saúde é condição básica para o desenvolvimento de uma prática médica adequada às reais necessidades de saúde da população (Campos; Pereira Júnior, 2016).

Vale ressaltar que, embora o PMM tenha promovido avanços significativos para expansão e a qualificação da $\mathrm{AB}$, publicações recentes (Campos; Pereira Júnior, 2016; Scheffer, 2016) têm alertado para entraves estruturais da Política Nacional de Atenção Básica (PNAB) que atravessam o Programa, além de seu caráter provisório e o tipo de vínculo de trabalho, que atrela trabalho e formação permanente sem, no entanto, estender a supervisão a toda equipe da Unidade Básica de Saúde. Tal fragmentação não contribui para o fortalecimento do modelo de gestão preconizado pelo SUS, que se assenta no fomento à autonomia e responsabilidade sanitária. Outros entraves da PNAB não viraram foco de investimento do PMM, como a baixa capacidade da $\mathrm{AB}$ de efetivamente coordenar o sistema de saúde e a falta de definição de carreiras para o SUS. Vínculos precários e instáveis ainda são um obstáculo à fixação dos médicos em algumas localidades, e a opção do PMM por vínculos temporários retarda o processo de responsabilização dos municípios em prover a contratação regular de médicos para a AB. Juntamente com esses desafios, resta à $\mathrm{AB}$ avançar para além da assistência médica, efetivando finalmente a interprofissionalidade e a intersetorialidade. O PMM abriga ainda a contradição de se apoiar em uma concepção de AB que reafirma a necessidade de superar a centralidade do médico, ao mesmo tempo que, enquanto Programa, desenha suas respostas assistenciais em torno desse profissional.

Entendemos que as lacunas históricas do SUS em torno do fortalecimento das organizações populares pode ter contribuído para a fragilização da garantia da continuidade da assistência, não permitindo que o PMM fosse concebido em outra base, focada não apenas no médico, mas nas equipes de $\mathrm{AB}$ e nos Núcleos de Apoio à Saúde da Família.

O PMM tem pela frente o desafio de um cenário em que a maioria dos médicos formados esteja inserida no setor público, e apenas $28 \%$ trabalhem exclusivamente no setor privado. 0 cenário tido como ideal da prática médica pelos profissionais ainda é o do especialista inserido em consultório privado, com atuação paralela em hospital privado de alto nível tecnológico. A inserção em unidades de saúde da rede pública e na emergência de prontoatendimento e hospitais da periferia segue vista com reticências por boa parte da categoria. A imagem da profissão vem se aproximando cada vez mais da dimensão tecnológica e comercial do trabalho, da prática especializada, da impessoalidade nas relações e da preocupação em se defender do jogo institucional. Tais práticas demonstram uma atitude defensiva diante das adversidades do trabalho em saúde, como a resistência em cumprir a carga horária contratada ou a tendência de oferecer uma assistência clínica diferenciada aos pacientes que pagam melhor. A mercantilização da atuação em saúde tem se expandido de tal modo que até dirigentes sindicais defendem interesses contrários aos interesses da população (Feuerwerker, 1998).

Qualquer movimento de transformação da formação precisa problematizar as atitudes contraditórias da categoria e, a nosso ver, a própria situação dos trabalhadores no SUS no contexto do mercado de trabalho atual. 0 debate sobre a formação 
deve envolver também a problemática da fixação de profissionais nos postos de trabalho e da carreira SUS. 0 modo como o mercado de trabalho interfere na formação e na prática profissional não pode ser subvalorizado, requerendo ampliação do diálogo, com inclusão de gestores da saúde e da sociedade civil organizada. Na saúde coletiva ainda persistem concepções reificadoras, que colocam trabalhadores como "recursos" do processo produtivo e usuários como "objetos" nos quais as ações de saúde intervêm.

A possibilidade de participar de espaços de discussão que abordem conceitos como saúde, produção de saúde, e modelos de atenção e de gestão interfere no modo como trabalhadores e gestores conceberão o lugar dos sujeitos no processo de produção de saúde. Se concebermos que trabalhadores, gestores e usuários devem ser sujeitos ativos e protagonistas do processo de produção de saúde, engendrando lutas cotidianas em defesa de suas necessidades, interesses e pontos de vista, temse aí um campo micropolítico a considerar.

Um dos maiores desafios para a mudança na política de formação é colocá-la como produto do diálogo com os impasses históricos que envolvem o trabalho médico. Um exemplo disso é o tema das diferenças salariais entre médicos e demais profissionais da saúde. A carga horária do curso de medicina, enquanto investimento de tempo de formação, é argumento de uso corrente para justificar a diferença salarial. Assim, permanece como um dos muitos desafios para a política pública de formação qualificar a formação médica para a atuação na $A B$ sem que tais mudanças se convertam em novo argumento a corroborar as já tão acentuadas assimetrias entre as profissões da saúde (Costa et al., 2014).

\section{Tensões e disputas: algumas perspectivas para a formação médica a partir do PMM}

As tentativas de mudanças curriculares induzidas pelas iniciativas governamentais procuraram incidir na relativização da força do modelo biológico, ampliando o diálogo com outros modelos, como o social. Mas essa relativização ainda está longe de terminar. Considerando que o complexo médicoindustrial exerce grande influência sobre o mercado de trabalho e, consequentemente, sobre as práticas de saúde, é natural que também tensione a formação médica para que esta se adéque a seus interesses. Assim, permanece viva entre os docentes - e também entre discentes - a lógica das especialidades como modo de organizar os saberes profissionais. Isso termina por afetar os conteúdos que interessam à formação para a $\mathrm{AB}$, perpetuando a fragmentação que corrobora a separação dos sujeitos, impossibilitando uma real prática coletiva (Pagliosa; Da Ros, 2008).

Nesse contexto, a autonomia das instituições formadoras para definir seu modo de funcionar é relativa, visto que também respondem aos diferentes projetos político-ideológicos dos grupos sociais inseridos no campo. As disputas entre esses grupos relacionam-se com outras forças sociais, como as entidades corporativas, movimentos sociais, a indústria e o mercado, com interesses na manutenção do complexo médico-industrial, partidos políticos, entre outros. O modo como essa complexa trama se constrói é que define se o projeto políticopedagógico será transformador ou reprodutor do modelo hegemônico. Ao que tudo indica, os grupos que defendem os modos já instituídos de formar têm demonstrado forte capacidade de desarticular os movimentos instituintes - aqueles que buscam impulsionar as mudanças (Campos; Pereira Júnior, 2016; Costa et al., 2014). Em resumo, a formação médica permanece sob várias influências: as macroestruturas, as tendências econômicas e políticas, a definição do que é saúde e do que são necessidades de saúde, os modos como se organizam a prática médica, os serviços e as políticas de saúde. Assim, apesar de haver real insuficiência de médicos no país, essa é apenas uma parte da questão.

A definição do quantitativo de médicos depende muito do modelo de atenção à saúde que se deseja instituir. É ele que orienta como e quais diferentes tecnologias comporão a caixa de ferramentas profissional e se esta dará conta de fomentar redes vivas, relações dialógicas e a construção coletiva de espaços colaborativos. Nesse sentido, Merhy (2013) aborda dimensões que vêm sendo subestimadas na formação em saúde. O plano no qual a clínica e o cuidado se dão é aquele do trabalho vivo, no 
campo produtivo do fazer, para além do plano do conhecimento. É nesse plano que o agir pedagógico opera e no qual se abre a disputa ético-política. Se tais dimensões não são incluídas no processo formativo e se não oferecemos abertura para que se visibilizem os vários regimes de verdade, impedimos a construção coletiva de ferramentas e soluções afinadas com as necessidades reais de trabalhadores e usuários. Talvez por isso muitas experiências de formação empreendam esforços didático-pedagógicos gigantescos para, ao final, reproduzirem a mesma lógica formativa que desejavam superar.

As publicações sobre o PMM o confirmam como estratégia potencialmente reordenadora da formação, visto ter sido elaborado a partir das reais necessidades do país e do SUS, colocando o Estado como agente regulador (Kemper; Mendonça; Sousa, 2016). Nesse sentido, os movimentos que vinham sendo realizados pelo PMM para promover a reestruturação e ampliação da formação médica em algum momento chegaram a polarizar as forças em disputa no campo. A centralização das informações sobre formação e distribuição de especialistas no país, a retirada do controle que as associações de especialidades médicas tinham sobre o planejamento e regulação da formação de especialistas e a definição da Medicina de Família e Comunidade como requisito de acesso a 10 especialidades médicas foram exemplos da radicalidade dessa interferência (Campos; Pereira Júnior, 2016). Como consequência dessa ação interventiva do Estado sobre a formação médica, houve alguma visibilização e acirramento das forças que disputavam um projeto nacional para esse campo, desvelando conservadorismos e lançando certa luz sobre as forças que precisam ser enfrentadas.

No entanto, a mudança política no cenário nacional em curso nos últimos dois anos, envolvendo a alternância dos grupos que estão à frente do Programa, tem trazido novos influxos aos rumos desse processo de mudança na formação médica. A necessidade governamental de realizar alianças políticas com vários segmentos sociais a fim de alcançar um pacto de governabilidade ameaça retirar do PMM boa parte de sua potência instituinte. As respostas das forças instituídas às tentativas mais robustas de transformação do statu quo são sempre proporcionais aos riscos reais de mudança. Trava-se, então, a partir do PMM, uma luta que não é apenas com o modelo médico hegemônico, mas com as próprias instituições que se sustentam a partir dele e de outras forças. Instituição aqui se reveste da acepção institucionalista, que a define como práticas sociais historicamente construídas, produtoras de verdades, objetos-saberes e modos de subjetivação (Heckert; Neves, 2007; Lourau, 1975).

A instituição medicina atravessa o tecido social com seus instituídos, com seus objetossaberes que definem o que é saúde, o que é ser médico, o que é a boa medicina etc. É com essas "verdades" historicamente construídas que se confrontam as mudanças propostas do PMM para a formação médica. Assim, não é apenas com os docentes formados no modo tradicional ou com a corporação médica que o PMM precisa construir pontes para o diálogo. É com a própria sociedade, incluindo aí os usuários do SUS, que entendem o processo saúdedoençaatenção a partir desse mesmo regime de verdades.

O que se coloca então para o PMM, e que precisa ser aprofundado nos novos cursos de medicina, é a necessidade de melhor explicitar o processo histórico que forjou a realidade e os sujeitos em campo. Uma estratégia já em curso é a organização ou o fortalecimento de movimentos instituintes, de agenciamento de sujeitos e grupos em torno da produção de espaços de reflexão, de diálogo e de invenção de propostas inovadoras.

A aposta que o PMM parece evocar é a da superação de lógicas e modelos formativos totalizantes, que desconsideram a multiplicidade, a pluralidade e as dimensões éticas e políticas em sua radicalidade. A associação de diferentes abordagens, perspectivas e estratégias pedagógicas que abranjam os desafios e a complexidade do trabalho em saúde e da formação voltada à atuação no SUS aparece como horizonte desejável, não apenas para a formação médica, mas para a formação em saúde de um modo geral.

Para potencializar o PMM em sua dimensão de dispositivo é fundamental compreender esse jogo de forças, explicitando os interesses em disputa. Desse modo, o PMM propiciará que a formação seja campo de tensão entre problematização e ação, capaz de agregar efetivamente novas dimensões não só à formação do médico, mas de todos os profissionais 
de saúde. Também é fundamental gerar espaços de diálogo e de produção de comum entre os diferentes atores, onde se possa reconhecer os modelos e paradigmas de formação que operam no campo e o modo como têm funcionado como regimes de verdades historicamente construídos.

\section{Considerações finais}

A formação médica precisa estar quantitativa e qualitativamente adequada às exigências do SUS, não só para garantir a universalidade e integralidade da atenção à saúde, mas também a sustentabilidade do próprio sistema de saúde (Da Ros, 2013). Mudar rígidas estruturas, romper acordos baseados no corporativismo, mobilizar docentes, superar as pressões exercidas pelo mercado de trabalho e pelo complexo industrial médico-hospitalar sobre o processo de formação profissional, são alguns dos desafios que se atualizam nos processos em andamento (Da Ros, 2013; Rovere, 1996).

Além da dimensão quantitativa, resta responder, então, como a formação avançará de sua orientação centrada em procedimentos e controles para outra focada nas necessidades dos usuários, na produção do cuidado e na afirmação da vida como multiplicidade. Se compreendermos a realidade como produção histórica e social, que acontece no entrecruzamento dos poderes e objetossaberes que circulam na sociedade, constituindo os sujeitos e seus modos de estar na vida, a frequente discussão sobre a função social do médico precisará ser recolocada. A nosso ver, não são os médicos, e sim a medicina, que precisa virar objeto de estudo e discussão nesses cursos. Não a medicina enquanto corpo teórico de conhecimentos técnicos, mas a medicina enquanto expressão do saberpoder de dada sociedade e de dada época. Aprofundar o debate sobre como se constituíram os diferentes modelos médicos, à luz do contexto histórico envolvido, atualiza na formação a dimensão social da própria medicina.

Apresentar a instituição medicina - enquanto produção sócio-histórica - como tema importante para os cursos de graduação implica oportunizar aos estudantes condições de se apropriar e se posicionar criticamente em relação àquele que será seu objeto de estudo ao longo de sua vida profissional. Talvez essa modulação permita aos futuros médicos perceber a importância de se agenciar em movimentos instituintes de mudança da prática médica desde a universidade.

As instituições refletem as forças que definem qual projeto de sociedade é hegemônico. A função social da instituição medicina pode ser justamente a de capitanear na saúde a fundamental discussão sobre o processo saúdedoençaatenção. Pode, finalmente, contribuir para a construção de uma concepção hegemônica de saúde que seja, enfim, afirmadora da vida em sua multiplicidade - uma tarefa nada banal.

\section{Referências}

ALMEIDA FILHO, N. Reconhecer Flexner: inquérito sobre produção de mitos na educação médica no Brasil contemporâneo. Cadernos de Saúde Pública, Rio de Janeiro, v. 26, n. 12, p. 2234-2249, 2010. Disponível em: <https://bit.ly/2ZkQ33s $>$. Acesso em: 15 out. 2018.

BRASIL. Ministério da Saúde. Portaria Interministerial $\mathrm{n}^{0} 1.802$, de 26 de agosto de 2008. Institui o Programa de Educação pelo Trabalho para a Saúde - PET-Saúde. Diário Oficial da União, Brasília, DF, 27 ago. 2008. Seção 1, p. 27.

BRASIL. Casa Civil. Lei $n^{0} 12.871$, de 22 de outubro de 2013. Institui o Programa Mais Médicos, altera as leis $n^{\circ} 8.745$, de 9 de dezembro de 1993 , e $n^{\circ} 6.932$, de 7 de julho de 1981, e dá outras providências. Diário Oficial da União, Brasília, DF, 23 out. 2013 . Seção 1, p. 1.

BRASIL. Ministério da Saúde. Secretaria de Gestão do Trabalho e da Educação na Saúde. Programa Mais Médicos, dois anos: mais saúde para os brasileiros. Brasília, DF: Ministério da Saúde, 2015.

CAMPOS, G. W. S.; PEREIRA JÚNIOR, N. A atenção primária e o Programa Mais Médicos do Sistema Único de Saúde: conquistas e limites. Ciência \& Saúde Coletiva, Rio de Janeiro, v. 21, n. 9 , p. 2655-2663, 2016.

CARVALHO, R. P. Cinaem: avaliação do ensino médico em nova fase. Jornal Medicina, Brasília, DF, n. 98, 1998. Disponível em: 〈https://bit.ly/2KEAeQQ〉. Acesso em: 20 fev. 2018. 
CEZAR, P. H. N. et al. Transição paradigmática na educação médica: um olhar construtivista dirigido à aprendizagem baseada em problemas. Revista Brasileira de Educação Médica, Rio de Janeiro, v. 34, n. 2, p. 298-303, 2010.

CHAVES, M.; KISIL, M. Origens, concepção e desenvolvimento. In: ALMEIDA, M. J.; FEUERWERKER, L.; LLANOS, M. (Org.). A educação dos profissionais de saúde na América Latina: teoria e prática de um movimento de mudança: tomo 1: um olhar analítico. São Paulo: Hucitec, 1999. p. 1-16.

COMES, Y. et al. Avaliação da satisfação dos usuários e da responsividade dos serviços em municípios inscritos no Programa Mais Médicos. Ciência \& Saúde Coletiva, Rio de Janeiro, v. 21, n. 9, p. 2749-2759, 2016.

COSTA, J. R. B. et al. A transformação curricular e a escolha da especialidade médica. Revista Brasileira de Educação Médica, Rio de Janeiro, v. 38, n. 1, p. 47-58, 2014.

DA ROS, M. A. Alguns comentários sobre o tema. Interface, Botucatu, v. 17, n. 47, p. 931-932, 2013.

FEUERWERKER, L. Mudanças na educação médica e na residência médica no Brasil. Interface, Botucatu, v. 2, n. 3, p. 51-71, 1998.

FEUERWERKER, L. Além do discurso de mudança na educação médica: processos e resultados. Rio de Janeiro: Hucitec, 2002.

FEUERWERKER, L. Médicos para o SUS: gestão do trabalho e da educação na saúde no olho do furacão! Interface, Botucatu, v. 17, n. 47, p. 929-930, 2013.

GOMES, A. P.; REGO, S. Paulo Freire: contribuindo para pensar mudanças de estratégias no ensino de medicina. Revista Brasileira de Educação Médica, Rio de Janeiro, v. 38, n. 3, p. 299-307, 2014.

GONZALEZ, A. D.; ALMEIDA, M. J. Movimentos de mudança na formação em saúde: da medicina comunitária às diretrizes curriculares. Physis, Rio de Janeiro, v. 20, n. 2, p. 551-570, 2010.

HECKERT, A. L. C.; NEVES, C. A. B. Modos de formar e modos de intervir: quando a formação se faz potência de produção de coletivo. In:
PINHEIRO, R.; BARROS, M. E. B.; MATTOS, R. A. (Org.). Trabalho em equipe sob o eixo da integralidade: valores, saberes e práticas. Rio de Janeiro: IMS/UERJ, 2007. p. 145-16o.

JUNQUEIRA, V.; FRUTUOSO, M. F. Os (des) compassos entre a universidade e os serviços de saúde. In: CAPOZOLLO, M. A. et al (Org.). Clínica comum: itinerários de uma formação em saúde.

São Paulo: Hucitec, 2013. p. 229-247.

KEMPER, E. S.; MENDONÇA, A. V. M.; SOUSA, M. F. Programa Mais Médicos: panorama da produção científica. Ciência \& Saúde Coletiva, Rio de Janeiro, v. 21, n. 9, p. 2785-2796, 2016.

LOURAU, R. A análise institucional. Petrópolis: Vozes, 1975 .

MATIAS, M. C. S. O desafio ético-estético-político do SUS para a formação médica: uma análise do Programa Mais Médicos. 2017. Tese (Doutorado em Saúde Coletiva) - Universidade Federal de Santa Catarina, Florianópolis, 2017.

MERHY, E. E. Vivenciar um campo de formação de profissionais de saúde: dobrando em mim o fazer da Unifesp - Baixada Santista (Prefácio). In: CAPOZOLLO, M. A. et al. (Org.). Clínica comum: itinerários de uma formação em saúde. São Paulo: Hucitec, 2013. p. 19-34.

OLIVEIRA, F. P. et al. Mais médicos: um programa brasileiro em uma perspectiva internacional. Interface, Botucatu, v. 19, n. 54, p. 623-634, 2015.

PAGLIOSA, F. L.; DA ROS, M. A. O relatório Flexner: para o bem e para o mal. Revista Brasileira de Educação Médica, Rio de Janeiro, v. 32, n. 4, p. 492-499, 2008.

ROVERE, M. R. Planificación estratégica de recursos humanos en salud. Washington, DC: Organización Panamericana de la Salud, 1996. (Desarrollo de Recursos Humanos, 96).

SCHEFFER, M. Para muito além do Programa Mais Médicos. Ciência \& Saúde Coletiva, Rio de Janeiro, v. 21, n. 9, p. 2664-2666, 2016.

SCHRAIBER, L. B. O médico e o seu trabalho: limites da liberdade. São Paulo: Hucitec, 1993. 
SILVA JUNIOR, A. G.; ANDRADE, H. S. Formação médica no Programa Mais Médicos: alguns riscos. Ciência \& Saúde Coletiva, Rio de Janeiro, v. 21, n. 9 , p. 2670-2671, 2016.
SOUZA, P. A.; ZEFERINO, A. M. B.; DA ROS, M. A. Currículo integrado: entre o discurso e a prática. Revista Brasileira de Educação Médica, Rio de Janeiro, v. 35, n. 1, p. 20-25, 2011.

\section{Contribuição dos autores}

Matias revisou a literatura e, com Verdi, delineou o projeto. Verdi, Finkler e Da Ros realizaram a revisão crítica do texto. Todos os autores analisaram e discutiram o tema, redigiram o manuscrito e aprovaram a versão final.

Recebido: 02/04/2019

Aprovado: 08/04/2019 